\title{
Retinoic Acid and Its Role in Modulating Intestinal Innate Immunity
}

\author{
Paulo Czarnewski, Srustidhar Das, Sara M. Parigi and Eduardo J. Villablanca * \\ Immunology and Allergy Unit, Department of Medicine, Solna, Karolinska Institutet and University Hospital, \\ Stockholm 171-76, Sweden; paulo.czarnewski@ki.se (P.C.); srustidhar.das@ki.se (S.D.); \\ martina.parigi@ki.se (S.M.P.) \\ * Correspondence: eduardo.villablanca@ki.se; Tel.: +46-08-5177-5934
}

Received: 1 November 2016; Accepted: 11 January 2017; Published: 13 January 2017

\begin{abstract}
Vitamin A (VA) is amongst the most well characterized food-derived nutrients with diverse immune modulatory roles. Deficiency in dietary VA has not only been associated with immune dysfunctions in the gut, but also with several systemic immune disorders. In particular, VA metabolite all-trans retinoic acid (atRA) has been shown to be crucial in inducing gut tropism in lymphocytes and modulating $\mathrm{T}$ helper differentiation. In addition to the widely recognized role in adaptive immunity, increasing evidence identifies atRA as an important modulator of innate immune cells, such as tolerogenic dendritic cells (DCs) and innate lymphoid cells (ILCs). Here, we focus on the role of retinoic acid in differentiation, trafficking and the functions of innate immune cells in health and inflammation associated disorders. Lastly, we discuss the potential involvement of $a t R A$ during the plausible crosstalk between DCs and ILCs.
\end{abstract}

Keywords: vitamin A; retinoic acid; innate immunity; dendritic cells; innate lymphoid cells

\section{Introduction}

Vitamin A (VA) is a lipophilic micronutrient obtained by dietary ingestion of primarily pro-vitamin A carotenoids (such as $\beta$-carotene) and retinyl esters (RE) derived from plant and animal food, respectively. Humans are not able to synthesize VA and thus depend on dietary replenishment for maintenance of several physiological processes throughout the body (reviewed in [1]). After intake, carotenes are enzymatically processed in the intestine to form retinol, which is transported from the lumen into the cell cytoplasm and is rapidly converted to RE or to retinoic acid (RA) [2]. All-trans-RA (atRA) is the physiologically most abundant and well-studied compared to other RA isoforms such as 9-cis-RA and 13-cis-RA. Since the current review focuses on the effect of RA on intestinal innate immunity, more detailed information on VA metabolism, absorption, and transportation to the peripheral tissues have been extensively reviewed elsewhere [3-6], which is beyond the scope of this review.

Micronutrient deficiency, in addition to protein-energy malnutrition (PEM), is being recognized as an important factor contributing towards the global burden of infectious diseases, particularly among children and pregnant women $[7,8]$. VA, among other micronutrients, has been closely associated with infection related morbidity and mortality in children [7]. Given the recent findings on the role of VA affecting both the innate and adaptive arms of the immune system, it seems plausible to implicate VA deficiency in increased susceptibility towards infectious diseases [7,8]. On the other hand, VA excess leads to deregulation of liver metabolic functions and presents several other toxic effects [9]. The role of VA metabolite atRA in adaptive immune responses has been extensively reviewed elsewhere [10-12], particularly in the context of intestinal immunity. Here, we review the recent findings where atRA plays a central role in the development and functioning of the innate arm of the immune system, in particular the myeloid compartment and innate lymphoid cells (ILCs). 


\section{Sources of atRA}

A major fraction of the dietary VA is stored in the hepatic stellate cells with the ability to transform VA/retinol to atRA [13,14]. However, in the intestine where dietary VA is absorbed and assimilated, several cell types are capable of metabolizing retinol to atRA. The conversion of retinol to retinaldehyde is mediated by alcohol dehydrogenases (ADHs), which are ubiquitously expressed, whereas the subsequent oxidation of retinaldehyde to atRA is mediated by one of the three retinaldehyde dehydrogenases (ALDHs) isoforms (ALDH1A1, ALDH1A2 and ALDH1A3), the expression of which is more restricted to atRA-producer cells [15]. In addition, RA can be degraded through cytochrome P450 family 26 (CYP26 family), the expression of which is distributed over several tissues and cell types [16,17]. Although atRA can influence the immune system in multiple organs, the intestinal immune system is one of the most affected and well-characterized ones [18]. Therefore, we have primarily focused on sources of at RA that affect the intestinal immune system.

Besides being the primary site for VA absorption, intestinal epithelial cells (IECs) can metabolize VA to RA by their ability to express ALDH1A1 [19,20]. However, our understanding of which IEC types are primarily responsible for metabolizing VA to RA is not complete. In addition, a subset of lamina propria stromal cells (LP-SCs) underlying IECs also express all ALDH isoforms and are able to metabolize VA [21]. Our knowledge about atRA-producer cells flourished after ALDEFLUOR (ALDE), a commonly used reagent in stem cell research, was used to label cells containing ALDH activity [22]. Using ALDE combined with specific cell surface markers, it is possible to determine that ALDH activity is restricted specifically to $\mathrm{CD} 103^{+} \mathrm{DC}$ but not $\mathrm{CD} 103^{-} \mathrm{DC}$ or any other hematopoietic-derived immune cell types in the intestine. This is in agreement with the expression of Aldh1a2 transcripts found uniquely on $\mathrm{CD}_{103^{+}}$DCs. Interestingly, DCs located at the proximal small intestine exhibit higher ALDH activity compared to DC located in the distal small intestine or colon [15,23], likely due to increased absorption of VA in the proximal part of the intestine. This correlates with gut-associated lymphoid tissue (GALT) DC functions, as seen in experiments in which DCs isolated form the proximal small intestine induced higher levels of Foxp3 ${ }^{+} \mathrm{T}_{\mathrm{REG}}$, gut homing molecules such as the CCR9 chemokine receptor and $\alpha 4 \beta 7$ integrin on T cells, and IgA class switching on B cells compared to DCs isolated from distal intestinal tissues [15]. Interestingly, CD103 ${ }^{+}$DCs are characterized by their ability to migrate towards the mesenteric lymph nodes (MLN) where these DCs are one of the predominant sources of atRA, important for generating gut-tropic T cells in mice [24,25].

Within MLN, multiple sources of atRA have been proposed, of which stromal cells and CD103 ${ }^{+}$ DCs are the best characterized [24-26]. The important contribution of atRA produced by MLN-derived stromal cells (MLN-SCs) stems from the study by the Oliver Pabst group in which peripheral lymph nodes (PLN) that do not express atRA-synthesizing enzymes when transplanted into the mesenteries resulted in diminished induction of gut-homing $\mathrm{T}$ cells [26]. In these experiments, even if the transplanted PLN is reconstituted with gut-derived DCs, the induction of gut-tropism was abolished [26], suggesting that atRA and/or other metabolite(s) produced specifically by resident MLN-SCs are critical for the induction of gut-homing receptors in T cells. In agreement, only MLN-SCs express atRA-synthesizing enzymes and support gut homing induction on $\mathrm{T}$ cells in vitro [26]. Interestingly, in the same study, bone marrow derived DCs (BM-DCs) that do not express atRA-synthesizing enzymes failed to induce gut homing receptors when injected directly into the MLN of CCR7-deficient mice [26]. This indicates that MLN-SC derived atRA is not sufficient for inducing gut tropism and may depend on lamina propria-derived DCs (which are absent in the C-C chemokine receptor type 7 (CCR7)-KO mice). Similarly, T cells adoptively transferred into CCR7-KO mice did not express gut-homing markers upon activation [27]. Further support towards the role of MLN-DCs stems from studies where MLN-DCs, characterized by the expression of atRA-synthesizing enzymes, are sufficient to induce gut homing receptors on $\mathrm{T}$ cells in vitro [28,29]. Are atRA-producer DCs sufficient for inducing gut tropism in vivo? Our unpublished data showed that subcutaneous injection of antigen-bearing atRA-producer DCs (e.g., MLN-DCs) were able to induce antigen-specific T cell activation and proliferation within the PLN but failed to induce gut-homing receptors, suggesting that 
DCs depends on the environment to induce gut tropism in vivo. This observation favors the notion that stromal cells from the MLN are essential to support atRA-mediated gut homing induction [26]. Another interpretation of these results is the possibility that the PLN displayed microenvironment-derived inhibitory signals towards the induction of gut homing receptors. Indeed, prostaglandin $\mathrm{E}_{2}\left(\mathrm{PGE}_{2}\right)$ has been shown to inhibit the induction of atRA-synthesizing enzymes (e.g., Aldh1a2) in DCs, and reduction of $\mathrm{PGE}_{2}$ synthesis in vivo results in the emergence of systemic atRA-synthesizing DCs [30]. It would be interesting then to explore the possibility of using gut-associated DCs as intradermal vaccines in the presence of $\mathrm{PGE}_{2}$ inhibitor to induce gut immune responses. Thus, it is likely that both MLN-SCs and DCs combine their functions to effectively produce and provide atRA and the consequent induction of gut-homing receptors on lymphocytes.

In summary, although VA can be metabolized to atRA by IECs, LP and MLN DCs, LP and MLN stromal cells, whether the contribution from each of these known players is sequential, cooperative and/or mutually exclusive needs further investigation. We hypothesize that whether atRA produced by one cell type is sufficient or needs to act together with other cell types depends largely on the biological context (e.g., steady-state versus disease). For instance, atRA produced by IECs may be sufficient for influencing colorectal cancer [19], whereas it might be required in both DCs and stromal cells to affect $\mathrm{T}$ cell priming and gut-homing [26,28].

\section{RA and Intestinal Homeostasis}

Among many nutrients and metabolites digested on a daily basis, VA orchestrates intestinal homeostasis and, in particular, intestinal immune homeostasis at multiple nodes [31]. Both the non-immune and immune cells in the gut are capable of producing and/or sensing atRA and therefore can contribute to the overall intestinal homeostasis. While the production of RA by multiple intestinal cell types depends on their ability to express ALDHs, the ability to sense RA is dependent on the expression of receptors that are broadly classified into two sub groups, i.e., retinoic acid receptor (RAR) and retinoid $X$ receptor (RXR). Furthermore, each sub group is comprised of three sub types such as $\operatorname{RAR} \alpha / \beta / \gamma$ and RXR $\alpha / \beta / \gamma$ [2,32]. Both atRA and 9-cis-RA can bind to and activate RAR that forms a heterodimer with the RXR, which then leads to transcriptional regulation of gene expression by binding to retinoic acid response elements (RARE). RXR, on the other hand, can be activated only by 9-cis-RA, although it can partner with several other nuclear receptors such as liver X receptor (LXR), peroxisome proliferator-activated receptor gamma (PPAR $\gamma$ ) etc. and affect gene expression [32]. The ability of various cell types in the intestine to sense and respond to RA is described in the following section.

Besides their role as a physical barrier, IECs can sense the luminal content and play essential roles in imprinting the underlying innate immune system [2], although intestinal epithelium is the first line the dietary metabolites encounter, if atRA acts on intestinal epithelial cells to modulate their development or function is poorly understood. Interestingly, experiments using zebrafish larvae suggest that atRA inhibits the differentiation of intestinal epithelial cells with mucosecretory phenotype, presumably goblet cells [33]. In agreement, unpublished data from our laboratory show that mice lacking RAR $\alpha$, specifically in IECs, result in goblet cell numbers that significantly outnumber their WT counterparts, suggesting a direct role of atRA in the intestinal epithelial cells' differentiation program. Although the effect of atRA in IECs is still an unexplored area, the ability of IECs to metabolize atRA has been extensively documented [1-3,19]. The recent work from Engleman and colleagues clearly demonstrated that healthy human colonic epithelium produce atRA, in contrast to the epithelium from inflammation-driven colorectal cancer patients that were compromised in their ability to produce atRA. This was shown to be a result of dramatic decrease in the expression of atRA synthesizing enzymes ALDH1A1 with concomitant increase in atRA degrading enzyme CYP26A1 in intestinal tissues from tumor-bearing compared to tumor-free mice [19]. Importantly, atRA supplementation reduced the tumor burden in a mouse model of colorectal cancer [19], highlighting the relevance of VA as a potential therapeutic option to treat colon cancer patients. In addition to the effects of atRA directly on the IECs, the epithelium mediates many of the immune responses by acting as a sensor of the 
environment and delivering cytokines and/or factors that modulate immune cell functions underlying the epithelial layer [34]. For instance, IEC produced atRA have been suggested to imprint tolerogenic functions in dendritic cells, a key step in the induction of oral tolerance to luminal antigens $[15,20,35]$.

A major advance in our understanding of VA as an immune modulator occurred in 2004 when Iwata and colleagues demonstrated that atRA was necessary and sufficient to induce the gut homing receptors, CCR9 and $\alpha 4 \beta 7$ on T cells [28]. This work was followed by Mora et al., showing that atRA induces gut tropism also on B cells [36]. Importantly, mice fed with VA-depleted (VAD) diet are almost devoid of $\mathrm{CD}^{+}$and $\mathrm{CD}^{+} \mathrm{T}$ as well as B cells in the small intestine lamina propria [28,36], highlighting the physiological importance of VA in intestinal lymphocyte homeostasis. Furthermore, intraepithelial lymphocytes (IELs), which are found abundantly in proximity to the intestinal epithelial cells, also rely on gut homing receptors to infiltrate the small intestine and position themselves at the epithelial site [37]. In agreement, mice expressing a dominant-negative form of the RAR $\alpha$, specifically in CD $4^{+}$ T cells, lack the CD4 ${ }^{+}$IEL population [38]. VA has also been shown to affect IgA secreting intestinal B cell homeostasis. For example, VA-deficient mice lack IgA antibody-secreting cells (IgA-ASCs) in the intestinal lamina propria. This has been attributed to a combinatorial effect of lack of atRA on impaired induction of gut homing receptors on IgA secreting B-cells and inability to synergize with the IL-6 or IL-5 production by DCs and/or other cells types [36]. In agreement, experiments depleting RAR $\alpha$ specifically in B cells render mice with intestinal microbiota dysbiosis and failure in developing adequate immune responses after oral immunization [39]. Thus, at RA has been shown to play important roles regulating adaptive immunity. Since the role of atRA modulating $\mathrm{T}$ cell homeostasis has been extensively reviewed elsewhere [10-12], we will further discuss its role as a modulator of the innate immune arm.

\section{RA in Dendritic Cells (DCs)}

Dendritic cells are characterized by their ability to sense and process antigens at peripheral tissues, and they migrate towards draining lymph nodes, produce specific cytokines and prime the differentiation of antigen-specific lymphocytes [40]. Hence, dendritic cells are specialized sentinels of our immune system capable of orchestrating the innate and adaptive immune response. Several of these functions of DCs are tightly regulated by atRA that acts at multiple nodes by influencing their differentiation and function. Although the majority of the studies are focused on intestinal DCs, some reports highlighted the role of atRA on myeloid cells beyond the intestine [41,42]. In the following section, we will discuss the effect of atRA in influencing DC differentiation from the bone marrow and their function in the periphery.

Based on their expression of $\alpha 4 \beta 7$ and their ability to preferentially give rise to intestinal CD103 ${ }^{+}$ DCs and CCR9 ${ }^{+}$plasmacytoid DCs, a specialized subset of precursors named pre- $\mu$ DCs (pre-mucosal DCs) has been identified in murine lymphoid organs and in the bone marrow [43] (Figure 1). In vitro differentiation studies proved the ability of atRA to dramatically expand pre- $\mu$ DCs among the total $\mathrm{BM}$ progenitors. In line with these findings, mice fed with a VAD diet resulted in a significant decrease in the BM pre- $\mu$ DCs pool [43]. This phenotype was coupled in the periphery by a selective reduction of $\mathrm{cDC} 2$ (or CD103 ${ }^{+} \mathrm{CD} 11 \mathrm{~b}^{+}$DCs) in the intestine and GALT [44] (Figure 1) and of the developmentally related $\mathrm{CD}_{11} \mathrm{~b}^{+} \mathrm{CD} 8 \mathrm{a}^{-}$Esam ${ }^{\text {hi }} \mathrm{DC}$ population in the spleen [45].

One of the current challenges in translational mucosal immunology is to identify the most efficient protocol to generate gut-like DCs that could be used as peripherally administered vaccines, enabling us to generate efficient mucosal immune responses. In vitro differentiation of pre- $\mu$ DCs in the presence of Fms-related tyrosine kinase 3 ligand (Flt3L), and granulocyte-macrophage colony-stimulating factor (GM-CSF) was not sufficient to recreate bona fide intestinal-like DCs [44]. Remarkably, addition of atRA was shown to direct the generation of DCs that mimicked the transcriptomic profile particularly of in vivo intestinal cDC subsets [44]. However, whether such in vitro generated DCs are functionally as competent as the in vivo cDCs remains to be tested. 


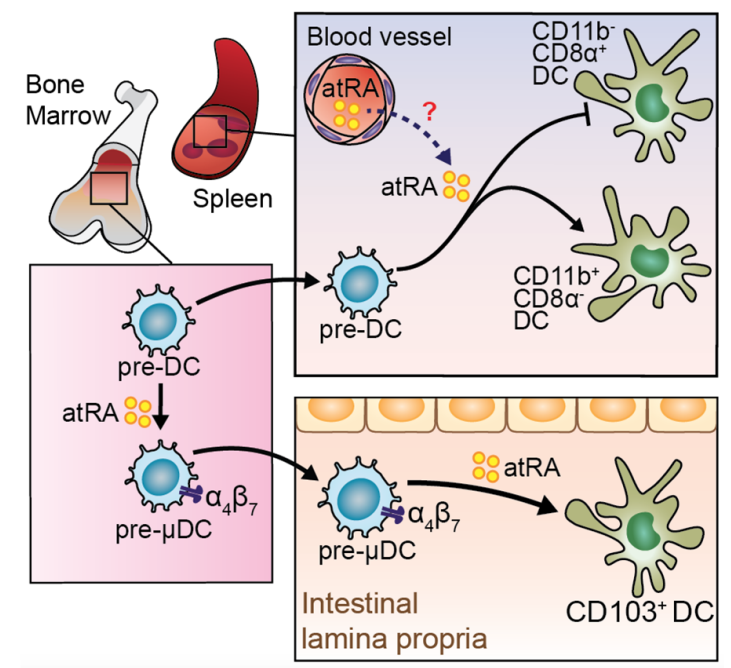

Figure 1. Role of all-trans retinoic acid (atRA) in regulating differentiation of dendritic cells (DC) precursors. Bone marrow (BM) resident pre-DCs have the potential to differentiate into pre-mucosal DC (pre- $\mu \mathrm{DC})$, characterized by the expression of gut homing receptors. Expansion of pre- $\mu \mathrm{DC}$ is atRA-dependent. Pre- $\mu$ DC gives rise to intestinal CD $103^{+} \mathrm{DCs}$, which is enhanced by the presence of atRA. Pre-DCs can migrate to the spleen, where they may sense atRA skewing the differentiation toward $\mathrm{CD} 11 \mathrm{~b}^{+} \mathrm{CD} 8^{-} \mathrm{DC}$ instead of $\mathrm{CD} 11 \mathrm{~b}^{-} \mathrm{CD} 8 \alpha^{+} \mathrm{DCs}$.

After differentiation and migration to the intestine, specific DC subsets are endowed with the ability to sense and respond to atRA [45]. The general consensus on the effect of atRA on DC function is to promote an anti-inflammatory phenotype characteristic of intestinal DCs [46,47]. Transcriptional profiling of in vitro differentiated DCs in the presence of atRA showed downregulation of pro-inflammatory genes involved in the NF-kB mediated inflammatory program [45]. However, besides the above-mentioned immuno-regulatory effects, some studies have emphasized a rather unorthodox pro-inflammatory role of atRA in DCs. In the presence of IL-15, atRA was shown to act as an adjuvant in promoting the secretion of the pro-inflammatory cytokines IL-12 and IL-23 by DCs [48]. Similarly, human DCs generated from monocytes in the presence of atRA primarily induced interferon gamma (IFN $\gamma$ ) production by $\mathrm{CD}^{+} \mathrm{T}$ cells in vitro [49]. The dual role of atRA in influencing DCs function might be a result of the microenvironments and/or cytokine milieu to which the DCs are exposed. For example, atRA in a cytokine environment that is either pro- or anti-inflammatory would induce a tolerogenic or pro-inflammatory DC phenotype, respectively.

Besides being able to sense and get influenced by atRA, DCs, in turn, are one of the main producers of atRA, a phenomenon that has been well-studied in intestinal $\mathrm{CD} 103^{+} \mathrm{DC}$ expressing high levels of the Aldh1a2 gene. This is most evident in the intestine where $\mathrm{CD}_{103^{+}} \mathrm{DCs}$ in the proximal tract of the small intestine are exposed to higher levels of atRA, which, in turn, renders them better atRA producers compared to distal small intestinal or colonic DCs. However, this is not limited to the intestine since extra intestinal DCs endowed with the ability to produce atRA have also been described, such as CD103- DCs in the skin [41]. Importantly, CD103- DCs in the skin can induce Foxp3 ${ }^{+} \mathrm{T}_{\text {REG }}$ similar to intestinal $\mathrm{CD}_{103^{+}}$DCs [41]. Several factors can influence DCs into atRA-producing cells. For example, incubation of DCs with atRA alone or in combination with various cytokines such as interleukin-4 (IL-4) and transforming growth factor beta (TGF $\beta$ ) cytokines were able to induce Aldh1a2 mRNA expression, which seems to be sufficient to render DCs with the capacity to metabolize atRA [50-52]. In addition, the short chain fatty acid butyrate was shown to induce Aldh1a expression in monocyte-derived dendritic cells, suggesting that microbiota-derived metabolites might play important roles in intestinal DC function [53]. Moreover, the Wnt pathway seems to be crucial in imprinting intestinal DCs since this pathway seems to be crucial to induce Aldh1a2 expression and produce atRA [54]. Furthermore, MyD88 signaling and, in particular, toll-like receptor (TLR) $1 / 2$ stimulation can also induce Aldh1a2 mRNA 
expression and imprint extra-intestinal DCs with atRA producing capacity $[15,55,56]$. While multiple factors and pathways have been shown to influence the atRA producing capacity of DCs, whether two or more of these pathways interact with each other needs to be investigated. Irrespective of the mechanism, DCs imprinted to produce atRA primarily induce a tolerogenic program by generation of Foxp3 $\mathrm{T}_{\text {REG }}$ cells. Importantly, atRA production by intestinal CD103 ${ }^{+}$DCs seems to be crucial for the generation of $\mathrm{T}_{\mathrm{REG}}$ and for the establishment of tolerance towards innocuous dietary antigens, a process known as oral tolerance.

\section{5. atRA-Producer Dendritic Cells in Oral Tolerance}

Local and systemic immune unresponsiveness towards antigens that have been previously administered by oral route is classically defined as oral tolerance [12,57]. These antigens, which are considered innocuous, are primarily derived from diet and failure to mount an effective tolerance towards these antigens has been associated with conditions such as food allergies and celiac disease. VA has proven crucial to the establishment of oral immunological tolerance against food antigens [12,57], and its deficiency might contribute towards food allergies, celiac disease and inflammatory bowel diseases (IBD). Indeed, mice deprived of VA resulted in exacerbated intestinal inflammation as assessed by colitis score and colon length using the dextran sodium sulfate (DSS)-induced colitis model [58]. Moreover, atRA supplementation efficiently attenuates chronic inflammation in a mouse model of ileitis [59]. Notably, atRA participates in more than one of the five-step models proposed for the establishment of oral immunological tolerance [12] (Figure 2).

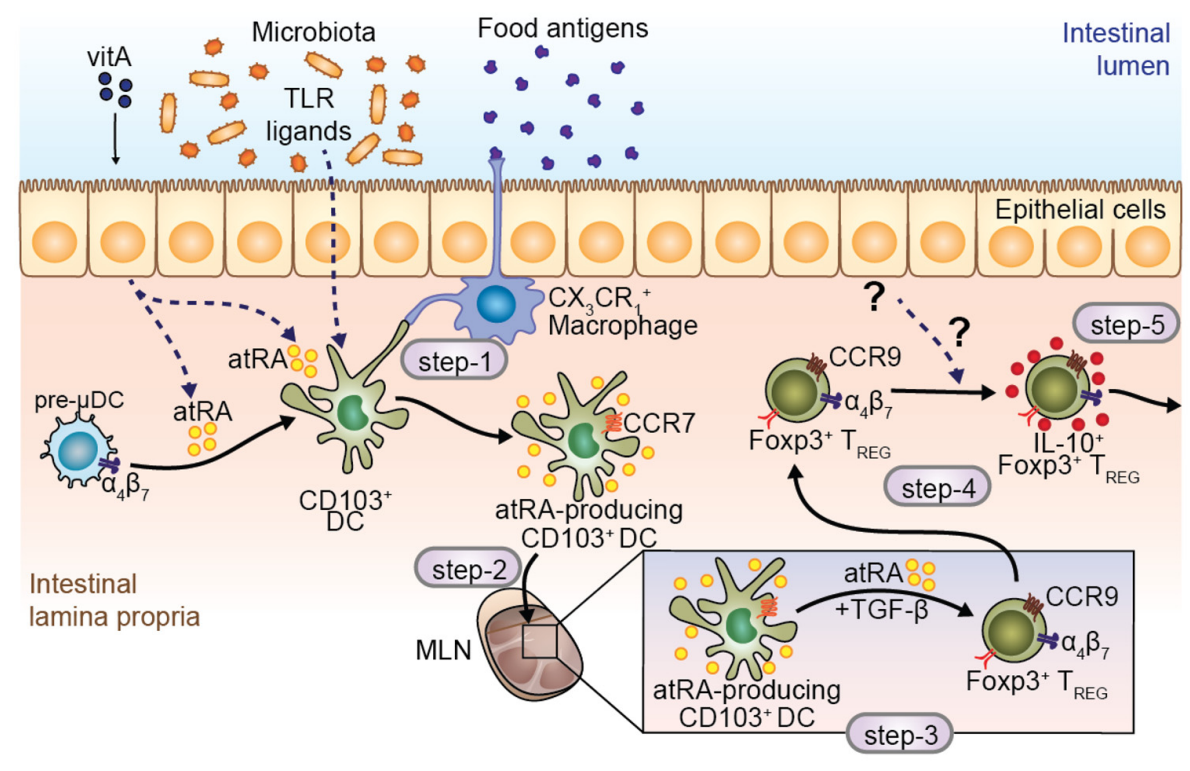

Figure 2. Role of atRA in modulating intestinal DC differentiation, maturation and function. $\mathrm{CD}_{103^{+}} \mathrm{DC}$ reside beneath the epithelial layer, in close contact with $\mathrm{CX} 3 \mathrm{CR} 1^{+}$macrophages, which are responsible for taking up luminal antigens and transferring them to $\mathrm{CD}_{103^{+}} \mathrm{DC}$ (step-1). Several molecules are described to induce atRA-producing $\mathrm{CCR}^{+} \mathrm{DCs}$, such as toll-like receptor (TLR) ligands and atRA itself, making DCs equipped to migrate to the mesenteric lymph nodes (MLN) (step-2). Within the MLN, CD103 ${ }^{+}$DCs are responsible for antigen presentation and differentiation of regulatory $\mathrm{T}$ cells in the presence of atRA and TGF- $\beta$ (step-3). Moreover, DC-derived atRA is crucial to induce the expression of gut homing receptors in T cells (step-3). Finally, regulatory $\mathrm{T}$ cells reach the intestinal mucosa and gain the capacity to produce IL-10, becoming IL-10 producing $\mathrm{T}_{\mathrm{REG}}$, which play a key role in the establishment of oral tolerance in the intestinal lamina propria (step-4); $\mathrm{T}_{\text {REG }}$ induced in this manner are able to migrate to peripheral tissues and promote tolerance (step-5). Steps 1 to 5 denote the main processes involved in the establishment of oral immunological tolerance. 
The first step involves pick up of antigens by $\mathrm{CX}_{3} \mathrm{CR} 1^{+}$macrophages and transfer to $\mathrm{CD} 103^{+}$ DCs [60] or by CD103 ${ }^{+}$DCs themselves [61] (Figure 2; step-1), which later will migrate towards the mesenteric lymph node (MLN). To reach the MLN (Figure 2; step-2), CD103 ${ }^{+}$DCs need to enter into the lymphatic vessels and move from CCL21-Leu to CCL21-Ser gradient present in the lymphatic endothelium in a chemokine receptor 7 (CCR7) dependent manner [62,63]. However, if atRA is essential for CCR7-dependent migration of DCs in vivo, is still unknown. Once in the MLN, antigen-bearing $\mathrm{CD}_{103}{ }^{+}$DCs encounter and prime antigen specific naïve $\mathrm{T}$ cells, which will differentiate to activated $\mathrm{T}$ helper cells. Depending on the microenvironment and cytokine milieu, $\mathrm{T}$ cells can become, among others, pro-inflammatory Th17 cells or immunosuppressive Foxp $3^{+}$regulatory $\mathrm{T}$ cells $\left(\mathrm{T}_{\mathrm{REG}}\right)$. During the establishment of oral tolerance, in step-3, the generation of antigen-specific Foxp3 ${ }^{+} \mathrm{T}_{\mathrm{REG}}$ is mandatory (Figure 2; step-3), in which stimulation of the T cell receptor (TCR), IL-2R and the TGF- $\beta$ receptor are required. In this setting, at RA acts as an adjuvant by enhancing the generation of Foxp3 ${ }^{+} \mathrm{T}_{\text {REG }}$ cells through the inhibition of Foxp3-inhibitory cytokine production by effector CD44 ${ }^{\text {hi }} \mathrm{T}$ cells [64] (Figure 3). In addition to enhanced $\mathrm{T}_{\text {REG }}$ differentiation, at RA may restrict Th17 differentiation $[35,65,66]$ and indirectly suppress $\mathrm{T}_{\mathrm{H}} 2$ inflammatory responses (reviewed in [10]) that may eventually favor the balance towards the generation of Foxp $3^{+} \mathrm{T}_{\text {REG }}$ cells. Indeed, a recent study showed that treatment of $\mathrm{T}_{\text {REG }}$ cells with atRA was able to preserve Foxp3 expression in these cells under Th17 polarizing conditions compared to the control [67]. In agreement, supplementation of atRA has been found to suppress $\mathrm{T}_{\mathrm{H}} 2$ and $\mathrm{T}_{\mathrm{H}} 17$ mediated inflammation in a mouse model of airway allergy [68,69]. However, whether atRA directly inhibits naïve $\mathrm{T}$ cells into $\mathrm{T}_{\mathrm{H}} 2$ phenotype or whether it enhances $\mathrm{T}_{\mathrm{H}}$ 2-supressor cells needs to be further explored.

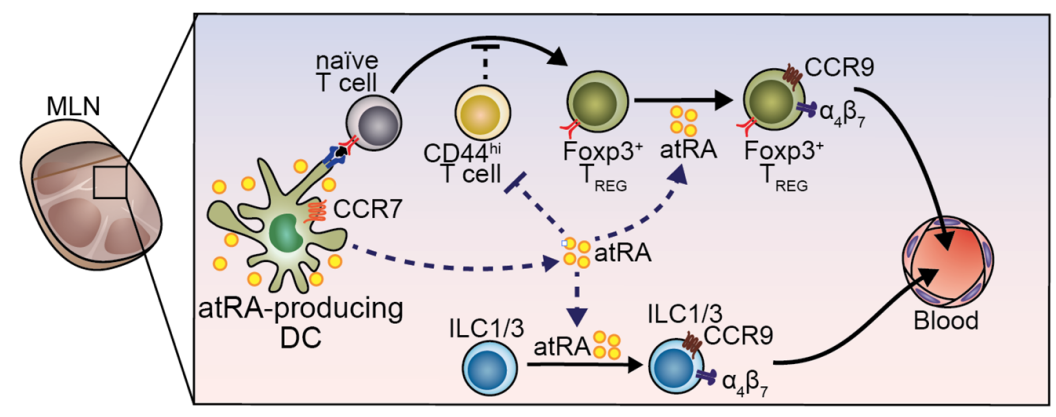

Figure 3. Role of DC-derived atRA in induction of gut-homing $\mathrm{T}_{\text {REG }}$ and innate lymphoid cells (ILCs). Mature DCs arrive in the MLN and are capable to produce atRA, as well as other stromal cells. atRA is important for generating $\mathrm{T}_{\text {REG }}$ by attenuating $C D 44^{\text {hi }}$ cells that inhibit $\mathrm{T}_{\text {REG }}$ differentiation. In addition, atRA in the MLN is crucial for induction of gut-homing receptors in T cells and in ILC1 and ILC3.

Interestingly, the crucial role of atRA in step-3 of oral tolerance establishment seems to be more related to the induction of gut-homing receptors rather than the generation of Foxp $3^{+} \mathrm{T}_{\text {REG }}$ per se. Once Foxp $3^{+} \mathrm{T}_{\text {REG }}$ expresses the integrin $\alpha 4 \beta 7$ and the chemokine receptor CCR 9 are generated in the MLN in an atRA-dependent manner, they are equipped to migrate towards the small intestine lamina propria [70], where they will expand and acquire the ability to produce IL-10 [70,71] (Figure 2; step-4). Fully differentiated IL-10 producing $\mathrm{T}_{\text {REG }}$ can enter the blood circulation and immunosuppress effector immune responses in peripheral tissues (Figure 2; step-5). Interestingly, mice fed with a VAD diet are not able to establish tolerance to orally administered antigens. Cassani et al. showed that adoptive transfer of in vitro generated antigen-specific gut-tropic $\mathrm{CD}^{+} \mathrm{T}$ cells into VAD mice was able to rescue oral tolerance to ovalbumin. This indicates that atRA is required for the induction of gut-tropism rather than expansion or full differentiation of Foxp3 ${ }^{+} \mathrm{T}_{\mathrm{REG}}$ at the lamina propria [70]. Moreover, CCR9-deficient Foxp3 ${ }^{+} \mathrm{T}_{\text {REG }}$ were not able to establish oral immunological tolerance [70], suggesting that atRA might be critical in inducing gut tropism rather than Foxp $3^{+} \mathrm{T}_{\mathrm{REG}}$. All together, 
these data suggest that atRA plays a critical role in inducing gut tropism on $\mathrm{T}_{\mathrm{REG}}$, which is an absolute requirement for establishing oral tolerance towards food antigens.

\section{RA in Regulation of ILC Development and Function}

Innate lymphoid cells (ILCs), a heterogeneous class of lymphocytes, are shown to be an important gatekeeper of immune homeostasis at the barrier sites of the body both in humans and mice [72]. The ILC family comprises NK (natural killer) cells and non-cytotoxic helper-like ILCs, distinguished by functional activity and developmental pathway. Based on cytokine production and key transcription factor expression, non-cytotoxic ILCs are further subdivided into three main subsets: ILC1 cells expressing T-bet mediate intracellular bacterial immunity by producing IFN- $\gamma$ and TNF- $\alpha$; ILC2 cells expressing GATA-3 are involved in immunity to helminthes, asthma and allergy through the production of IL-4, IL-5 and IL-13; and ILC3 cells expressing ROR $\gamma t$ that can further be subdivided into LTi (lymphoid tissue inducer cell, described in a separate section below) and cells producing IL-17, IL-22 and GM-CSF contributing to intestinal homeostasis and protection towards extracellular bacteria [73]. Unlike T cells, the lineage specification decision does not require antigen-specific priming. Instead, it is decided during development from ILC-committed progenitors in the bone marrow [74].

VA and atRA have been extensively studied as regulator of ILC development and function. Similar to T cells, ILC migration to the intestine upon development and maturation can be tightly regulated by atRA. Common ILC precursors (CHILPs) in the bone marrow are equipped with $\alpha 4 \beta 7$ integrin expression [75]. However, whether this phenomenon is atRA-dependent remains unaddressed. While BM-resident ILC2 committed progenitors (ILC2P) can directly migrate to the gastrointestinal tract in a CCR9- and $\beta 7$-dependent way, ILC1 and ILC3 migrate first to the MLN in a CCR7-dependent manner where they undergo homing receptors switching to then migrate to the gut [76] (Figure 4). Homing tropism switch in ILC1 and ILC3 has been demonstrated in co-culture experiments, in which MLN DC-derived atRA was responsible for CCR7 downregulation and $\alpha 4 \beta 7$ and CCR9 upregulation [75]. Nevertheless, whether the interaction between ILCs and DCs takes place in vivo in the MLN remains to be unraveled. Paralleling these results in mice, in vitro experiments using human fluorescence-activated cell sorting (FACS)-purified ILCs from peripheral blood proved the ability of atRA, in concert with IL-2, to induce $\alpha 4 \beta 7$ [77]. Of note, this effect was abolished when the hormonally active form of vitamin $\mathrm{D}, 1,25$-dihydroxyvitamin $\mathrm{D}_{3}\left(1,25-(\mathrm{OH})_{2} \mathrm{D}_{3}\right)$ was added to the culture [77], suggesting a potential antagonistic effect of these two vitamins on gut-homing induction. Interestingly, VA sufficiency was proven to be dispensable for the expression of gut-homing receptors on bone marrow ILC2P [75] and rather act as a negative regulator of ILC2 differentiation [78]. ILC2P or mature ILC2 treated with atRA resulted in reduced expression of IL-7Ra and subsequent proliferative potential [78]. Consistently, mice fed with a VAD diet displayed increased ILC2 in the intestinal lamina propria with the consequent improved ILC2-mediated resistance to helminthic infection [78].

RA is also instrumental in fine tuning functional activity of mature ILCs in the tissue. By enhancing the production of IL-22 in natural cytotoxicity receptor (NCR) ${ }^{+}$ILC3 and lymph node-derived $\gamma \delta$ $\mathrm{T}$ cells, atRA was shown to attenuate colonic inflammation provoked by DSS administration or by Citrobacter rodentium infection [78,79]. The proposed mechanism was a direct binding of RARs to the Il-22 promoter, thus directly regulating Il-22 mRNA transcription [79]. However, while a putative RAR $\gamma$ motif was bound by RARs in the IL-22 promoter, the main isoform found to be enriched on mouse $\mathrm{NCR}^{+}$ILC3 [79], and its human equivalent NKp44 ${ }^{+}$ILC3 [80], was RAR $\alpha$. Therefore, which is the relative contribution of these two isoforms in regulating IL-22 expression in ILCs still remains to be addressed. Besides regulating the functions of differentiated ILC3, atRA has been shown to foster the plasticity between mature ILC subsets. Indeed, in vitro studies demonstrated that atRA, in concert with IL-23 and IL-1 $\beta$, accelerates the conversion of ILC1 to ILC3 and their IL-22 production potential [80] (Figure 4). Interestingly, this process was recreated by simply co-culturing ILC1 with intestinal CD14- DCs, further supporting the hypothesis of a central role of DCs in directing ILCs function through RA [80]. 


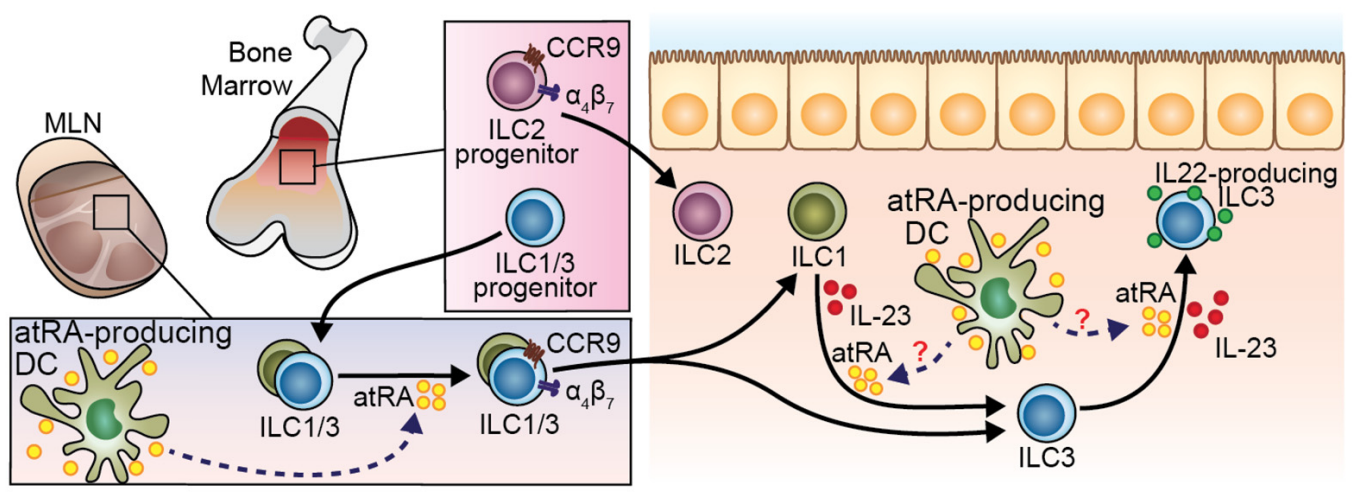

Figure 4. Role of atRA modulating ILC migration and function. ILC2 progenitors in the bone marrow (BM) express gut-homing receptors and migrate to the intestine independently of atRA. On the other hand, ILC1 and ILC3 progenitors deploy from the BM to the MLN. DC-derived atRA induce the expression of gut-homing molecules on ILC1 and ILC3 there, conferring the ability to migrate to the intestinal mucosa. Once in the gut tissue, ILC1 can potentially differentiate into ILC3 in the presence of IL-23. This plasticity may be enhanced by IL-1 $\beta$ and atRA. IL-23 induces IL-22 production by ILC3, which can be enhanced by atRA.

It is well established that the concentrations of atRA in the small intestine follows a proximal (i.e., duodenum) to distal (i.e., colon) decreasing gradient $[15,23]$. Similarly, ILC subsets are differentially distributed along the gastrointestinal tract with ILC3 outnumbering ILC1 and ILC2 in the small intestine, whereas ILC2 are predominant in the colon [78]. Therefore, it is tempting to speculate that atRA might be one of the players involved in the complex functional regionalization of ILCs in the intestine, likely by controlling their migration, differentiation and/or function.

\section{RA Influence on Lymphoid Organogenesis}

Lymphoid organogenesis is a stepwise process that occurs during embryonic development and involves the concerted activity of different cell types [81]. RA sufficiency throughout the entire process has been shown to be instrumental and influences the function(s) of the different immune and non-immune players involved. The earliest step in lymphoid organogenesis requires the expression of the chemokine Cxcl13 by mesenchymal organizer cells [82]. In vitro and in vivo studies demonstrated that atRA is pivotal in inducing C $x c l 13$ expression through RAR $\beta$ activation with consequent formation of the lymph node anlagen [82]. Notably, atRA required for this process is most likely produced by nerve fibers expressing Aldh1a2 that colocalize with stromal cells in the anlagen [82]. Upon sensing of C-X-C motif chemokine ligand 13 (CXCL13), LTi cells are attracted towards the primordial lymphoid structure and contribute to lymphoid organogenesis by communicating with surrounding stromal cells through lympotoxin- $\alpha / \beta$ expression. LTi cells belong to the class of ILC3 and are instrumental for the formation of lymph nodes such as Peyer's Patches (PP) in the small intestine [83], and cryptopatches and isolated lymphoid follicles in the colon [84]. Similar to other ILC3 subsets, they express the transcription factor ROR $\gamma t$ that has been proven to be crucial for their generation. Mice deficient in ROR $\gamma \mathrm{t}$ are characterized by the absence of PP, PLN and MLN [83]. LTi are also characterized by the expression of RA receptors (RAR $\alpha, R A R \beta$ and $R A R \gamma$ ) and conditional deletion of RAR $\alpha$ in fetal LTi intrinsically affects their differentiation and subsequently the development of secondary lymphoid organs [85]. Mechanistically, a direct regulation of Ror $\gamma t$ expression by atRA responsive elements upstream and within the Rorc locus has been suggested [85]. Remarkably, atRA influences LTi prenatally and the maternal dietary intake of VA or atRA levels in utero are fundamental to controlling the size of the lymphocyte pool and the resistance to infection in the offspring [85]. In addition to LTi cells, DCs have been recently shown to be crucial to inducing PLN maturation. It was shown that fungi-sensitized intestinal $\mathrm{CD} 103^{+} \mathrm{ALDH}^{+} \mathrm{DCs}$ can migrate to and promote maturation of neonatal 
PLN by downregulating MAdCAM-1 and upregulating PNAd expression in PLN endothelial cells, which, in turn, allow its maturation and homing of T cells to the small intestine [86]. Taken together, these studies emphasize the importance of dietary VA and RA as non-redundant early building blocks for a functional immune system.

\section{Conclusions}

Recent studies support the role of atRA as an important enhancer of DC differentiation and migration from the bone marrow to the intestine, ultimately resulting in DCs that are capable of both sensing and producing atRA. In addition, atRA works as a crucial regulator of DC function, which dictates $\mathrm{T}$ helper and effector cell function in the mucosal sites and in peripheral tissues. Interestingly, the cytokine milieu can influence DCs to induce pro-inflammatory T helper functions, even in the presence of atRA. Finally, recent advances in the ILC field point towards atRA-producing DCs as modulators of ILC migration, function and phenotype plasticity. Taken together, atRA exerts a crucial role in DC function in order to maintain tolerance against food and microbial antigens and promote tissue homeostasis.

Acknowledgments: We thank members of the Villablanca lab (Stockholm, Sweden) for helpful comments. This work was supported by funding from a Swedish Research Council VR grant K2015-68X-22765-01-6 and the Wallenberg Academy Fellow (WAF) program.

Author Contributions: P.C. designed and made the figures. P.C. and E.J.V. outlined the manuscript. P.C., S.D., S.M.P. and E.J.V. revised the literature and wrote the manuscript.

Conflicts of Interest: The authors declare no competing financial interests.

\section{References}

1. Harrison, E.H. Mechanisms of digestion and absorption of dietary vitamin A. Annu. Rev. Nutr. 2005, 25, 87-103. [CrossRef] [PubMed]

2. Larange, A.; Cheroutre, H. Retinoic acid and retinoic acid receptors as pleiotropic modulators of the immune system. Annu. Rev. Immunol. 2016, 34, 369-394. [CrossRef] [PubMed]

3. D'Ambrosio, D.N.; Clugston, R.D.; Blaner, W.S. Vitamin A metabolism: An update. Nutrients 2011, 3, 63-103. [CrossRef] [PubMed]

4. Reboul, E. Absorption of vitamin A and carotenoids by the enterocyte: Focus on transport proteins. Nutrients 2013, 5, 3563-3581. [CrossRef] [PubMed]

5. Tanumihardjo, S.A.; Russell, R.M.; Stephensen, C.B.; Gannon, B.M.; Craft, N.E.; Haskell, M.J.; Lietz, G.; Schulze, K.; Raiten, D.J. Biomarkers of nutrition for development (bond)-vitamin A review. J. Nutr. 2016, 146, 1816S-1848S. [CrossRef] [PubMed]

6. Chelstowska, S.; Widjaja-Adhi, M.A.; Silvaroli, J.A.; Golczak, M. Molecular basis for vitamin A uptake and storage in vertebrates. Nutrients 2016, 8, 676. [CrossRef] [PubMed]

7. Bhaskaram, P. Micronutrient malnutrition, infection, and immunity: An overview. Nutr. Rev. 2002, 60, S40-S45. [CrossRef] [PubMed]

8. Black, R. Micronutrient deficiency-An underlying cause of morbidity and mortality. Bull. World Health Organ. 2003, 81, 79. [PubMed]

9. Penniston, K.L.; Tanumihardjo, S.A. The acute and chronic toxic effects of vitamin A. Am. J. Clin. Nutr. 2006, 83, 191-201. [PubMed]

10. Bono, M.R.; Tejon, G.; Flores-Santibanez, F.; Fernandez, D.; Rosemblatt, M.; Sauma, D. Retinoic acid as a modulator of T cell immunity. Nutrients 2016, 8. [CrossRef] [PubMed]

11. Liu, Z.M.; Wang, K.P.; Ma, J.; Guo Zheng, S. The role of all-trans retinoic acid in the biology of Foxp3 ${ }^{+}$ regulatory T cells. Cell. Mol. Immunol. 2015, 12, 553-557. [CrossRef] [PubMed]

12. Villablanca, E.J. Retinoic acid-producing DCs and gut-tropic FOXP3 ${ }^{+}$regulatory $\mathrm{T}$ cells in the induction of oral tolerance. Oncoimmunology 2013, 2, e22987. [CrossRef] [PubMed]

13. Lee, Y.S.; Jeong, W.I. Retinoic acids and hepatic stellate cells in liver disease. J. Gastroenterol. Hepatol. 2012, 27, 75-79. [CrossRef] [PubMed] 
14. Ichikawa, S.; Mucida, D.; Tyznik, A.J.; Kronenberg, M.; Cheroutre, H. Hepatic stellate cells function as regulatory bystanders. J. Immunol. 2011, 186, 5549-5555. [CrossRef] [PubMed]

15. Villablanca, E.J.; Wang, S.; de Calisto, J.; Gomes, D.C.; Kane, M.A.; Napoli, J.L.; Blaner, W.S.; Kagechika, H.; Blomhoff, R.; Rosemblatt, M.; et al. MyD88 and retinoic acid signaling pathways interact to modulate gastrointestinal activities of dendritic cells. Gastroenterology 2011, 141, 176-185. [CrossRef] [PubMed]

16. Xi, J.; Yang, Z. Expression of RALDHs (ALDH1As) and CYP26s in human tissues and during the neural differentiation of P19 embryonal carcinoma stem cell. Gene Expr. Patterns 2008, 8, 438-442. [CrossRef] [PubMed]

17. Theodosiou, M.; Laudet, V.; Schubert, M. From carrot to clinic: An overview of the retinoic acid signaling pathway. Cell. Mol. Life Sci. 2010, 67, 1423-1445. [CrossRef] [PubMed]

18. Hall, J.A.; Grainger, J.R.; Spencer, S.P.; Belkaid, Y. The role of retinoic acid in tolerance and immunity. Immunity 2011, 35, 13-22. [CrossRef] [PubMed]

19. Bhattacharya, N.; Yuan, R.; Prestwood, T.R.; Penny, H.L.; DiMaio, M.A.; Reticker-Flynn, N.E.; Krois, C.R.; Kenkel, J.A.; Pham, T.D.; Carmi, Y.; et al. Normalizing microbiota-induced retinoic acid deficiency stimulates protective CD8+ T cell-mediated immunity in colorectal cancer. Immunity 2016, 45, 641-655. [CrossRef] [PubMed]

20. Iliev, I.D.; Mileti, E.; Matteoli, G.; Chieppa, M.; Rescigno, M. Intestinal epithelial cells promote colitis-protective regulatory T-cell differentiation through dendritic cell conditioning. Mucosal Immunol. 2009, 2, 340-350. [CrossRef] [PubMed]

21. Vicente-Suarez, I.; Larange, A.; Reardon, C.; Matho, M.; Feau, S.; Chodaczek, G.; Park, Y.; Obata, Y.; Gold, R.; Wang-Zhu, Y.; et al. Unique lamina propria stromal cells imprint the functional phenotype of mucosal dendritic cells. Mucosal Immunol. 2015, 8, 141-151. [CrossRef] [PubMed]

22. Yokota, A.; Takeuchi, H.; Maeda, N.; Ohoka, Y.; Kato, C.; Song, S.Y.; Iwata, M. Gm-CSF and IL-4 synergistically trigger dendritic cells to acquire retinoic acid-producing capacity. Int. Immunol. 2009, 21, 361-377. [CrossRef] [PubMed]

23. McDonald, K.G.; Leach, M.R.; Brooke, K.W.; Wang, C.; Wheeler, L.W.; Hanly, E.K.; Rowley, C.W.; Levin, M.S.; Wagner, M.; Li, E.; et al. Epithelial expression of the cytosolic retinoid chaperone cellular retinol binding protein II is essential for in vivo imprinting of local gut dendritic cells by lumenal retinoids. Am. J. Pathol. 2012, 180, 984-997. [CrossRef] [PubMed]

24. Persson, E.K.; Uronen-Hansson, H.; Semmrich, M.; Rivollier, A.; Hagerbrand, K.; Marsal, J.; Gudjonsson, S.; Hakansson, U.; Reizis, B.; Kotarsky, K.; et al. IRF4 transcription-factor-dependent CD103(+)CD11b(+) dendritic cells drive mucosal $\mathrm{T}$ helper 17 cell differentiation. Immunity 2013, 38, 958-969. [CrossRef] [PubMed]

25. Edelson, B.T.; Kc, W.; Juang, R.; Kohyama, M.; Benoit, L.A.; Klekotka, P.A.; Moon, C.; Albring, J.C.; Ise, W.; Michael, D.G.; et al. Peripheral $\mathrm{CD}_{103^{+}}$dendritic cells form a unified subset developmentally related to CD8alpha $^{+}$conventional dendritic cells. J. Exp. Med. 2010, 207, 823-836. [CrossRef] [PubMed]

26. Hammerschmidt, S.I.; Ahrendt, M.; Bode, U.; Wahl, B.; Kremmer, E.; Forster, R.; Pabst, O. Stromal mesenteric lymph node cells are essential for the generation of gut-homing T cells in vivo. J. Exp. Med. 2008, 205, 2483-2490. [CrossRef] [PubMed]

27. He, W.; Racine, J.J.; Johnston, H.F.; Li, X.; Li, N.; Cassady, K.; Liu, C.; Deng, R.; Martin, P.; Forman, S.; et al. Depletion of host CCR7(+) dendritic cells prevented donor $\mathrm{T}$ cell tissue tropism in anti-CD3-conditioned recipients. Biol. Blood. Marrow. Transpl. 2014, 20, 920-928. [CrossRef] [PubMed]

28. Iwata, M.; Hirakiyama, A.; Eshima, Y.; Kagechika, H.; Kato, C.; Song, S.Y. Retinoic acid imprints gut-homing specificity on T cells. Immunity 2004, 21, 527-538. [CrossRef] [PubMed]

29. Mora, J.R.; Bono, M.R.; Manjunath, N.; Weninger, W.; Cavanagh, L.L.; Rosemblatt, M.; von Andrian, U.H. Selective imprinting of gut-homing T cells by peyer's patch dendritic cells. Nature 2003, 424, 88-93. [CrossRef] [PubMed]

30. Stock, A.; Booth, S.; Cerundolo, V. Prostaglandin E2 suppresses the differentiation of retinoic acid-producing dendritic cells in mice and humans. J. Exp. Med. 2011, 208, 761-773. [CrossRef] [PubMed]

31. Cassani, B.; Villablanca, E.J.; de Calisto, J.; Wang, S.; Mora, J.R. Vitamin A and immune regulation: Role of retinoic acid in gut-associated dendritic cell education, immune protection and tolerance. Mol. Asp. Med. 2012, 33, 63-76. [CrossRef] [PubMed] 
32. Kam, R.K.; Deng, Y.; Chen, Y.; Zhao, H. Retinoic acid synthesis and functions in early embryonic development. Cell Biosci. 2012, 2, 11. [CrossRef] [PubMed]

33. Oehlers, S.H.; Flores, M.V.; Hall, C.J.; Crosier, K.E.; Crosier, P.S. Retinoic acid suppresses intestinal mucus production and exacerbates experimental enterocolitis. Dis. Model. Mech. 2012, 5, 457-467. [CrossRef] [PubMed]

34. Chatterjee, A.; Gogolak, P.; Blottiere, H.M.; Rajnavolgyi, E. The impact of ATRA on shaping human myeloid cell responses to epithelial cell-derived stimuli and on T-lymphocyte polarization. Mediat. Inflamm. 2015, 2015, 579830. [CrossRef] [PubMed]

35. Mucida, D.; Park, Y.; Kim, G.; Turovskaya, O.; Scott, I.; Kronenberg, M.; Cheroutre, H. Reciprocal Th17 and regulatory $\mathrm{T}$ cell differentiation mediated by retinoic acid. Science 2007, 317, 256-260. [CrossRef] [PubMed]

36. Mora, J.R.; Iwata, M.; Eksteen, B.; Song, S.Y.; Junt, T.; Senman, B.; Otipoby, K.L.; Yokota, A.; Takeuchi, H.; Ricciardi-Castagnoli, P.; et al. Generation of gut-homing IGA-secreting B cells by intestinal dendritic cells. Science 2006, 314, 1157-1160. [CrossRef] [PubMed]

37. Agace, W. Generation of gut-homing T cells and their localization to the small intestinal mucosa. Immunol. Lett. 2010, 128, 21-23. [CrossRef] [PubMed]

38. Reis, B.S.; Rogoz, A.; Costa-Pinto, F.A.; Taniuchi, I.; Mucida, D. Mutual expression of the transcription factors Runx3 and ThPOK regulates intestinal CD4(+) T cell immunity. Nat. Immunol. 2013, 14, 271-280. [CrossRef] [PubMed]

39. Pantazi, E.; Marks, E.; Stolarczyk, E.; Lycke, N.; Noelle, R.J.; Elgueta, R. Cutting edge: Retinoic acid signaling in B cells is essential for oral immunization and microflora composition. J. Immunol. 2015, 195, 1368-1371. [CrossRef] [PubMed]

40. Worbs, T.; Hammerschmidt, S.I.; Forster, R. Dendritic cell migration in health and disease. Nat. Rev. Immunol. 2017, 17, 30-48. [CrossRef] [PubMed]

41. Guilliams, M.; Crozat, K.; Henri, S.; Tamoutounour, S.; Grenot, P.; Devilard, E.; de Bovis, B.; Alexopoulou, L.; Dalod, M.; Malissen, B. Skin-draining lymph nodes contain dermis-derived CD103(-) dendritic cells that constitutively produce retinoic acid and induce Foxp3(+) regulatory T cells. Blood 2010, 115, 1958-1968. [CrossRef] [PubMed]

42. Khare, A.; Krishnamoorthy, N.; Oriss, T.B.; Fei, M.; Ray, P.; Ray, A. Cutting edge: Inhaled antigen upregulates retinaldehyde dehydrogenase in lung $\mathrm{CD}_{103^{+}}$but not plasmacytoid dendritic cells to induce Foxp3 de novo in $\mathrm{CD}^{+} \mathrm{t}$ cells and promote airway tolerance. J. Immunol. 2013, 191, 25-29. [CrossRef] [PubMed]

43. Zeng, R.; Oderup, C.; Yuan, R.; Lee, M.; Habtezion, A.; Hadeiba, H.; Butcher, E.C. Retinoic acid regulates the development of a gut-homing precursor for intestinal dendritic cells. Mucosal Immunol. 2013, 6, 847-856. [CrossRef] [PubMed]

44. Zeng, R.; Bscheider, M.; Lahl, K.; Lee, M.; Butcher, E.C. Generation and transcriptional programming of intestinal dendritic cells: Essential role of retinoic acid. Mucosal Immunol. 2016, 9, 183-193. [CrossRef] [PubMed]

45. Klebanoff, C.A.; Spencer, S.P.; Torabi-Parizi, P.; Grainger, J.R.; Roychoudhuri, R.; Ji, Y.; Sukumar, M.; Muranski, P.; Scott, C.D.; Hall, J.A.; et al. Retinoic acid controls the homeostasis of pre-CDC-derived splenic and intestinal dendritic cells. J. Exp. Med. 2013, 210, 1961-1976. [CrossRef] [PubMed]

46. Sun, C.M.; Hall, J.A.; Blank, R.B.; Bouladoux, N.; Oukka, M.; Mora, J.R.; Belkaid, Y. Small intestine lamina propria dendritic cells promote de novo generation of Foxp3 T reg cells via retinoic acid. J. Exp. Med. 2007, 204, 1775-1785. [CrossRef] [PubMed]

47. Coombes, J.L.; Siddiqui, K.R.; Arancibia-Carcamo, C.V.; Hall, J.; Sun, C.M.; Belkaid, Y.; Powrie, F. A functionally specialized population of mucosal $\mathrm{CD}_{103^{+}} \mathrm{DC}$ induces Foxp3 ${ }^{+}$regulatory $\mathrm{T}$ cells via a TGF-beta and retinoic acid-dependent mechanism. J. Exp. Med. 2007, 204, 1757-1764. [CrossRef] [PubMed]

48. DePaolo, R.W.; Abadie, V.; Tang, F.; Fehlner-Peach, H.; Hall, J.A.; Wang, W.; Marietta, E.V.; Kasarda, D.D.; Waldmann, T.A.; Murray, J.A.; et al. Co-adjuvant effects of retinoic acid and IL-15 induce inflammatory immunity to dietary antigens. Nature 2011, 471, 220-224. [CrossRef] [PubMed]

49. Rampal, R.; Awasthi, A.; Ahuja, V. Retinoic acid-primed human dendritic cells inhibit Th9 cells and induce Th1/Th17 cell differentiation. J. Leukocyte Biol. 2016, 100, 111-120. [CrossRef] [PubMed] 
50. Ohoka, Y.; Yokota-Nakatsuma, A.; Maeda, N.; Takeuchi, H.; Iwata, M. Retinoic acid and GM-CSF coordinately induce retinal dehydrogenase 2 (RALDH2) expression through cooperation between the RAR/RXR complex and Sp1 in dendritic cells. PLoS ONE 2014, 9, e96512. [CrossRef] [PubMed]

51. Bakdash, G.; Vogelpoel, L.T.; van Capel, T.M.; Kapsenberg, M.L.; de Jong, E.C. Retinoic acid primes human dendritic cells to induce gut-homing, IL-10-producing regulatory T cells. Mucosal Immunol. 2015, 8, 265-278. [CrossRef] [PubMed]

52. Agrawal, S.; Ganguly, S.; Tran, A.; Sundaram, P.; Agrawal, A. Retinoic acid treated human dendritic cells induce $T$ regulatory cells via the expression of CD141 and garp which is impaired with age. Aging 2016, 8, 1223-1235. [CrossRef] [PubMed]

53. Singh, N.; Gurav, A.; Sivaprakasam, S.; Brady, E.; Padia, R.; Shi, H.; Thangaraju, M.; Prasad, P.D.; Manicassamy, S.; Munn, D.H.; et al. Activation of GPR109A, receptor for niacin and the commensal metabolite butyrate, suppresses colonic inflammation and carcinogenesis. Immunity 2014, 40, 128-139. [CrossRef] [PubMed]

54. Manicassamy, S.; Reizis, B.; Ravindran, R.; Nakaya, H.; Salazar-Gonzalez, R.M.; Wang, Y.C.; Pulendran, B. Activation of beta-catenin in dendritic cells regulates immunity versus tolerance in the intestine. Science 2010, 329, 849-853. [CrossRef] [PubMed]

55. Wang, S.; Villablanca, E.J.; de Calisto, J.; Gomes, D.C.; Nguyen, D.D.; Mizoguchi, E.; Kagan, J.C.; Reinecker, H.C.; Hacohen, N.; Nagler, C.; et al. MyD88-dependent TLR1/2 signals educate dendritic cells with gut-specific imprinting properties. J. Immunol. 2011, 187, 141-150. [CrossRef] [PubMed]

56. Feng, T.; Cong, Y.; Qin, H.; Benveniste, E.N.; Elson, C.O. Generation of mucosal dendritic cells from bone marrow reveals a critical role of retinoic acid. J. Immunol. 2010, 185, 5915-5925. [CrossRef] [PubMed]

57. Pabst, O.; Mowat, A.M. Oral tolerance to food protein. Mucosal Immunol. 2012, 5, 232-239. [CrossRef] [PubMed]

58. Okayasu, I.; Hana, K.; Nemoto, N.; Yoshida, T.; Saegusa, M.; Yokota-Nakatsuma, A.; Song, S.Y.; Iwata, M. Vitamin A inhibits development of dextran sulfate sodium-induced colitis and colon cancer in a mouse model. Biomed. Res. Int. 2016, 2016, 4874809. [CrossRef] [PubMed]

59. Collins, C.B.; Aherne, C.M.; Kominsky, D.; McNamee, E.N.; Lebsack, M.D.; Eltzschig, H.; Jedlicka, P.; Rivera-Nieves, J. Retinoic acid attenuates ileitis by restoring the balance between T-helper 17 and T regulatory cells. Gastroenterology 2011, 141, 1821-1831. [CrossRef] [PubMed]

60. Mazzini, E.; Massimiliano, L.; Penna, G.; Rescigno, M. Oral tolerance can be established via gap junction transfer of fed antigens from CX3CR1(+) macrophages to CD103(+) dendritic cells. Immunity 2014, 40, 248-261. [CrossRef] [PubMed]

61. Farache, J.; Koren, I.; Milo, I.; Gurevich, I.; Kim, K.W.; Zigmond, E.; Furtado, G.C.; Lira, S.A.; Shakhar, G. Luminal bacteria recruit $\mathrm{CD}_{103^{+}}$dendritic cells into the intestinal epithelium to sample bacterial antigens for presentation. Immunity 2013, 38, 581-595. [CrossRef] [PubMed]

62. Randolph, G.J.; Angeli, V.; Swartz, M.A. Dendritic-cell trafficking to lymph nodes through lymphatic vessels. Nat. Rev. Immunol. 2005, 5, 617-628. [CrossRef] [PubMed]

63. Forster, R.; Davalos-Misslitz, A.C.; Rot, A. CCR7 and its ligands: Balancing immunity and tolerance. Nat. Rev. Immunol. 2008, 8, 362-371. [CrossRef] [PubMed]

64. Hill, J.A.; Hall, J.A.; Sun, C.M.; Cai, Q.; Ghyselinck, N.; Chambon, P.; Belkaid, Y.; Mathis, D.; Benoist, C. Retinoic acid enhances Foxp3 induction indirectly by relieving inhibition from CD4 ${ }^{+} \mathrm{CD} 44^{\text {hi }}$ cells. Immunity 2008, 29, 758-770. [CrossRef] [PubMed]

65. Xiao, S.; Jin, H.; Korn, T.; Liu, S.M.; Oukka, M.; Lim, B.; Kuchroo, V.K. Retinoic acid increases Foxp3 ${ }^{+}$ regulatory $\mathrm{T}$ cells and inhibits development of Th17 cells by enhancing TGF-beta-driven Smad3 signaling and inhibiting IL-6 and IL-23 receptor expression. J. Immunol. 2008, 181, 2277-2284. [CrossRef] [PubMed]

66. Elias, K.M.; Laurence, A.; Davidson, T.S.; Stephens, G.; Kanno, Y.; Shevach, E.M.; O'Shea, J.J. Retinoic acid inhibits Th17 polarization and enhances Foxp3 expression through a Stat-3/Stat-5 independent signaling pathway. Blood 2008, 111, 1013-1020. [CrossRef] [PubMed]

67. Tejon, G.; Manriquez, V.; de Calisto, J.; Flores-Santibanez, F.; Hidalgo, Y.; Crisostomo, N.; Fernandez, D.; Sauma, D.; Mora, J.R.; Bono, M.R.; et al. Vitamin A impairs the reprogramming of tregs into IL-17-producing cells during intestinal inflammation. Biomed. Res. Int. 2015, 2015, 137893. [CrossRef] [PubMed] 
68. Wu, J.; Zhang, Y.; Liu, Q.; Zhong, W.; Xia, Z. All-trans retinoic acid attenuates airway inflammation by inhibiting Th2 and Th17 response in experimental allergic asthma. BMC Immunol. 2013, 14, 28. [CrossRef] [PubMed]

69. Yokota-Nakatsuma, A.; Takeuchi, H.; Ohoka, Y.; Kato, C.; Song, S.Y.; Hoshino, T.; Yagita, H.; Ohteki, T.; Iwata, M. Retinoic acid prevents mesenteric lymph node dendritic cells from inducing IL-13-producing inflammatory Th2 cells. Mucosal Immunol. 2014, 7, 786-801. [CrossRef] [PubMed]

70. Cassani, B.; Villablanca, E.J.; Quintana, F.J.; Love, P.E.; Lacy-Hulbert, A.; Blaner, W.S.; Sparwasser, T.; Snapper, S.B.; Weiner, H.L.; Mora, J.R. Gut-tropic T cells that express integrin alpha4beta7 and CCR9 are required for induction of oral immune tolerance in mice. Gastroenterology 2011, 141, 2109-2118. [CrossRef] [PubMed]

71. Hadis, U.; Wahl, B.; Schulz, O.; Hardtke-Wolenski, M.; Schippers, A.; Wagner, N.; Muller, W.; Sparwasser, T.; Forster, R.; Pabst, O. Intestinal tolerance requires gut homing and expansion of Foxp3 ${ }^{+}$regulatory $\mathrm{T}$ cells in the lamina propria. Immunity 2011, 34, 237-246. [CrossRef] [PubMed]

72. Sonnenberg, G.F.; Artis, D. Innate lymphoid cells in the initiation, regulation and resolution of inflammation. Nat. Med. 2015, 21, 698-708. [CrossRef] [PubMed]

73. Spits, H.; Artis, D.; Colonna, M.; Diefenbach, A.; Di Santo, J.P.; Eberl, G.; Koyasu, S.; Locksley, R.M.; McKenzie, A.N.; Mebius, R.E.; et al. Innate lymphoid cells-A proposal for uniform nomenclature. Nat. Rev. Immunol. 2013, 13, 145-149. [CrossRef] [PubMed]

74. Serafini, N.; Vosshenrich, C.A.; di Santo, J.P. Transcriptional regulation of innate lymphoid cell fate. Nat. Rev. Immunol. 2015, 15, 415-428. [CrossRef] [PubMed]

75. Kim, M.H.; Taparowsky, E.J.; Kim, C.H. Retinoic acid differentially regulates the migration of innate lymphoid cell subsets to the gut. Immunity 2015, 43, 107-119. [CrossRef] [PubMed]

76. Klose, C.S.; Flach, M.; Mohle, L.; Rogell, L.; Hoyler, T.; Ebert, K.; Fabiunke, C.; Pfeifer, D.; Sexl, V.; Fonseca-Pereira, D.; et al. Differentiation of type 1 ILCs from a common progenitor to all helper-like innate lymphoid cell lineages. Cell 2014, 157, 340-356. [CrossRef] [PubMed]

77. Ruiter, B.; Patil, S.U.; Shreffler, W.G. Vitamins A and D have antagonistic effects on expression of effector cytokines and gut-homing integrin in human innate lymphoid cells. Clin. Exp. Allergy 2015, 45, 1214-1225. [CrossRef] [PubMed]

78. Spencer, S.P.; Wilhelm, C.; Yang, Q.; Hall, J.A.; Bouladoux, N.; Boyd, A.; Nutman, T.B.; Urban, J.F., Jr.; Wang, J.; Ramalingam, T.R.; et al. Adaptation of innate lymphoid cells to a micronutrient deficiency promotes type 2 barrier immunity. Science 2014, 343, 432-437. [CrossRef] [PubMed]

79. Mielke, L.A.; Jones, S.A.; Raverdeau, M.; Higgs, R.; Stefanska, A.; Groom, J.R.; Misiak, A.; Dungan, L.S.; Sutton, C.E.; Streubel, G.; et al. Retinoic acid expression associates with enhanced IL-22 production by gammadelta T cells and innate lymphoid cells and attenuation of intestinal inflammation. J. Exp. Med. 2013, 210, 1117-1124. [CrossRef] [PubMed]

80. Bernink, J.H.; Krabbendam, L.; Germar, K.; de Jong, E.; Gronke, K.; Kofoed-Nielsen, M.; Munneke, J.M.; Hazenberg, M.D.; Villaudy, J.; Buskens, C.J.; et al. Interleukin-12 and -23 control plasticity of CD127(+) group 1 and group 3 innate lymphoid cells in the intestinal lamina propria. Immunity 2015, 43, 146-160. [CrossRef] [PubMed]

81. Van de Pavert, S.A.; Vivier, E. Differentiation and function of group 3 innate lymphoid cells, from embryo to adult. Int. Immunol. 2016, 28, 35-42. [CrossRef] [PubMed]

82. Van de Pavert, S.A.; Olivier, B.J.; Goverse, G.; Vondenhoff, M.F.; Greuter, M.; Beke, P.; Kusser, K.; Hopken, U.E.; Lipp, M.; Niederreither, K.; et al. Chemokine CXCL13 is essential for lymph node initiation and is induced by retinoic acid and neuronal stimulation. Nat. Immunol. 2009, 10, 1193-1199. [CrossRef] [PubMed]

83. Eberl, G.; Marmon, S.; Sunshine, M.J.; Rennert, P.D.; Choi, Y.; Littman, D.R. An essential function for the nuclear receptor rorgamma $(\mathrm{t})$ in the generation of fetal lymphoid tissue inducer cells. Nat. Immunol. 2004, 5, 64-73. [CrossRef] [PubMed]

84. Colonna, M. Interleukin-22-producing natural killer cells and lymphoid tissue inducer-like cells in mucosal immunity. Immunity 2009, 31, 15-23. [CrossRef] [PubMed] 
85. Van de Pavert, S.A.; Ferreira, M.; Domingues, R.G.; Ribeiro, H.; Molenaar, R.; Moreira-Santos, L.; Almeida, F.F.; Ibiza, S.; Barbosa, I.; Goverse, G.; et al. Maternal retinoids control type 3 innate lymphoid cells and set the offspring immunity. Nature 2014, 508, 123-127. [CrossRef] [PubMed]

86. Zhang, Z.; Li, J.; Zheng, W.; Zhao, G.; Zhang, H.; Wang, X.; Guo, Y.; Qin, C.; Shi, Y. Peripheral lymphoid volume expansion and maintenance are controlled by gut microbiota via $\mathrm{RALDH}^{+}$dendritic cells. Immunity 2016, 44, 330-342. [CrossRef] [PubMed]

(C) 2017 by the authors; licensee MDPI, Basel, Switzerland. This article is an open access article distributed under the terms and conditions of the Creative Commons Attribution (CC-BY) license (http://creativecommons.org/licenses/by/4.0/). 